\title{
Disease-Free Survival of Colorectal Cancer Patients in Relation to CDw75 Antigen Expression
}

\author{
Susana Villar-Portela ${ }^{a}$ Laura Muinelo-Romay ${ }^{a}$ Elisa Cuevas ${ }^{b}$ Emilio Gil-Martín ${ }^{a}$ \\ Almudena Fernández-Briera ${ }^{a}$ \\ a Department of Biochemistry, Genetics and Immunology, Faculty of Biology, University of Vigo, Vigo, and \\ ${ }^{b}$ Pathology Service, University Hospital Complex, Ourense, Spain
}

\section{Key Words}

CDw75 $\cdot \alpha(2,6)$-Sialylation $\cdot$ Colorectal cancer $\cdot$ Prognostic value

\begin{abstract}
Objective: CDw75 is an $\alpha(2,6)$-sialylated antigen associated with a poor prognosis in gastric cancer. In the present study, we examined if CDw75 expression in colorectal cancer (CRC) predicts tumour recurrence. Besides, we evaluated CDw75 expression in different colorectal tissue specimens to clarify their role in tumour development and progression. Methods: We analyzed CDw75 expression in 34 specimens of healthy disease-free colorectal mucosa, 19 specimens of inflammatory colorectal mucosa, 73 colorectal adenomas, 35 specimens of healthy tissue and 101 specimens of tumoural tissue from CRC patients. Results: None of the healthy disease-free and inflammatory colorectal mucosa specimens showed the presence of the epitope. CDw75 was expressed in $26 \%$ of the colorectal adenomas. In healthy and tumoural tissue from CRC patients, CDw75 was detected in $22.9 \%$ and $82.2 \%$ of the specimens, respectively. CDw75 expression in tumoural tissue was correlated with growth pattern $(p=$ $0.044)$, Dukes stage $(p=0.002)$, TNM stage $(p=0.020)$ and distant metastasis $(p=0.005)$. Survival analysis showed that CDw75 expression is not associated with tumour recurrence.
\end{abstract}

Conclusion: CDw75 expression in CRC is not a prognostic factor for predicting disease-free survival. Nevertheless, CDW75 expression may be a good marker of tumour progression and of the malignant potential of CRC.

Copyright $\odot 2011$ S. Karger AG, Basel

\section{Introduction}

Compositional and structural alterations in cell surface glycoconjugates are commonly occur during malignant transformation [1]. One of the most frequent changes observed in tumour cell surface glycoconjugates is the increase in sialic acid linked to carbohydrate antenna residues. It is known that the sialylation of membrane components influences the metastatic potential of tumour cells [2]. Sialic acid residues are mainly found at terminal positions of glycoprotein and glycolipid oligosaccharide chains. They may be $\alpha-2,3$ - and/or $\alpha-2,6$-linked to galactose $(\mathrm{Gal}), \alpha(2,6)$-linked to $\mathrm{N}$-acetylgalactosamine (Gal$\mathrm{Nac}$ ) or N-acetylglucosamine (GlcNAc), as well as $\alpha(2,8)$ linked to other sialic acids in a specific post-transcriptional modification of $\mathrm{N}$ chains known as polysialic acid.

E.G.-M. and A.F.-B. contributed equally to this work.

\section{KARGER}

Fax +41613061234 E-Mail karger@karger.ch www.karger.com
(ㄷ) 2011 S. Karger AG, Basel

$1015-2008 / 11 / 0784-0201 \$ 38.00 / 0$

Accessible online at:

www.karger.com/pat
Almudena Fernández Briera

Department of Biochemistry, Genetics and Immunology, Faculty of Biology

University of Vigo, Campus As Lagoas-Marcosende

ES-36310 Vigo (Spain)

Tel. +34 986812 573, E-Mail abriera@ uvigo.es 
The synthesis of these different sialyl linkages is catalyzed by different members of the sialyltransferase family, a class of glycosyltransferases [3].

CDw75 is a cell surface antigen synthesized by the $\beta$-galactosyl $\alpha(2,6)$-sialyltransferase (ST6Gal I) and expressed by the majority of $\mathrm{B}$ cells. The enzyme transfers a sialic acid residue from CMP-NeuAc to a Gal $\beta(1,4)$ GlcNAc (lactosamine) sequence located in the terminal chains of cell surface and serum N-glycoproteins [4]. ST6Gal II is another enzyme with $\alpha(2,6)$-sialyltransferase activity, the main acceptor of which is a free lactosamine sequence [5, 6]. Several studies have reported a significant increase in ST6Gal I activity in colorectal tumours compared with healthy colorectal mucosa [7-10]. Moreover, high activity levels of ST6Gal I in metastasizing colorectal tumours were found to be related to a poor prognosis $[8,11]$.

CDw75 antigen is a ligand for CD22 (siglec-2), an inhibitor coreceptor in B lymphocytes that controls the signalling threshold of B cell receptors [12]. It has been widely studied in blood cells neoplasias [13-16] and in solid tumours, such as benign breast lesions and carcinomas, as well as in gastro-intestinal carcinomas [17-21]. Several studies have reported increased CDw75 expression in gastric and colorectal tumours compared with healthy gastric and colorectal mucosa [19-21]. Moreover, CDw75 expression in gastric carcinomas has been associated with tumour progression and a worse prognosis $[19,21]$. Regarding colorectal cancer (CRC), although CDw75 expression has been correlated with the malignant potential [20], the prognostic value of this antigen has not been described.

In a recent study, our group reported an increase in both CDw75 expression and ST6Gal I activity in CRC, as well as a possible implication of CDw75 in CRC development [22]. In the present study, we examined whether the expression of CDw75 antigen in CRC is associated with tumour recurrence. Besides, in an attempt to clarify the role of CDw75 in the development and progression of CRC, we analyzed its expression profile in different colorectal specimens that show the progressive malignant transformation of colorectal tissue, from healthy disease-free mucosa to adenocarcinoma.

\section{Materials and Methods}

Patients

CRC tissue specimens were obtained from 101 patients with CRC, diagnosed and treated between 2000 and 2004 at the University Hospital Complex (CHOU, Ourense, Spain). Tissue specimens of healthy mucosa (at a distance at least $10 \mathrm{~cm}$ from the pri- mary carcinoma) were obtained from 35 of the above-mentioned CRC patients. Tumour staging was carried out by means of the TNM classification system described by the International Union against Cancer (UICC) [23]. In addition, 73 colorectal adenomas, 19 biopsies of colorectal inflammatory mucosa and 34 biopsies of healthy disease-free colorectal mucosa, obtained from CRC-free individuals, were included. Patients who underwent primary colorectal tumour resection were followed for at least 5 years or until disease recurrence or death. Patients who died within 30 days after surgery or with distant metastasis at surgical resection were excluded from the follow-up. All procedures involving human samples were performed according to the clinical practices of the 'Xunta de Galicia' and followed the tenets of the Helsinki Declaration.

\section{Immunohistochemical Analysis}

All fresh specimens were fixed in formalin $(10 \% \mathrm{v} / \mathrm{v})$ and embedded in paraffin. Sections $(3 \mu \mathrm{m})$ from selected paraffin-embedded tissue blocks were deparaffinized in xylene, hydrated in a graded ethanol series, and heated for $15 \mathrm{~min}$ in $0.1 \mathrm{M}$ citric acid buffer ( $\mathrm{pH}$ 6.0) in a microwave oven to unmask the epitopes. Endogenous peroxidase activity was blocked by using a commercial solution (Peroxidase block, EnVision ${ }^{\mathrm{TM}}$ Detection System; Dako, Calif., USA) for $15 \mathrm{~min}$. To avoid non-specific binding, the tissue slides were incubated for 20 min with $2 \%$ bovine serum (SigmaAldrich, St. Louis, Mo., USA). Afterwards, the sections were incubated with the primary antibody against CDw75 (dilution 1/25, clone LN-1; Neomarkers, Fremont, Calif., USA) in a moist chamber for $30 \mathrm{~min}$. After rinsing with PBS, the incubation with the secondary antibody bound to peroxidase (goat anti-mouse labelled polymer, HRP, EnVision ${ }^{\mathrm{TM}}$ Detection System) was carried out for $30 \mathrm{~min}$ in a moist chamber. The immunostaining was then visualized with 3,3'-diaminobenzidine reagent (EnVision ${ }^{\mathrm{TM}} \mathrm{De}$ tection System). Finally, the sections were counterstained with haematoxylin, dehydrated through a graded ethanol series and xylene, and mounted in Dpex mounting medium. Negative controls were performed by replacing the primary antibody with PBS.

\section{Evaluation of CDw75 Staining}

The immunohistochemical staining, detected as a brown colour precipitate, was evaluated independently by two pathologists from $\mathrm{CHOU}$, who reached a final result by consensus. The staining scores were classified semiquantitatively as follows: $0=$ no staining, 1 = weak staining intensity, 2 = moderate staining intensity and 3 = strong staining intensity.

\section{Statistical Analysis}

Statistical analysis was performed using the PASW Statistics 18 program. Univariate analysis for categorical data was conducted by means of the $\chi^{2}$ test or Fisher's exact probability test. For continuous data, we employed Wilcoxon's test and the MannWhitney U test. Disease-free survival rates were calculated by the Kaplan-Meier method [24] and differences between the survival curves were analyzed by the log-rank test [25]. Multivariate Cox regression analysis [26], using the forward stepwise data selection method, was carried out to determine the factors with independent prognostic value. The results were considered significant when $\mathrm{p}<0.05$. 
Fig. 1. Immunohistochemical expression of CDw75. Sections from a healthy disease-free colorectal mucosa (a) and an inflammatory colorectal mucosa (b) showing no CDw75 expression. Sections from a colorectal adenoma specimen (c), a colorectal healthy specimen (d) and a colorectal tumour specimen $(\mathbf{e}, \mathbf{f})$ with positive CDw75 staining, evidenced by the presence of a brown precipitate (color refers to the online version). Scale bars $=25 \mu \mathrm{m}$.
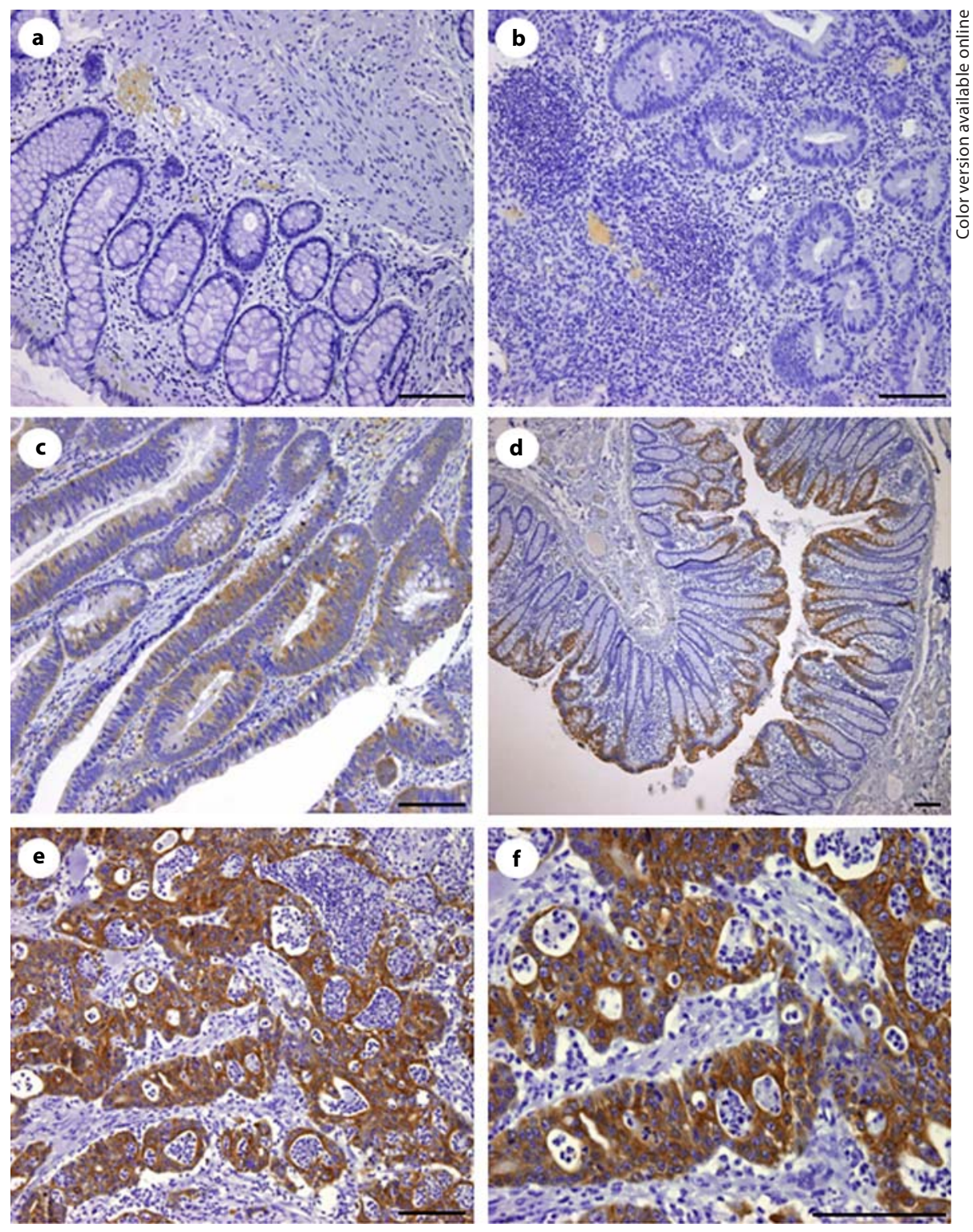

\section{Results}

Expression of CDw75 Antigen in Colorectal Specimens

No positive CDw75 antigen expression was found in healthy disease-free and inflammatory mucosa from CRC-free patients (fig. 1a, b). However, CDw75 expression was visualized as a brown staining located on the cytoplasm and the plasma membrane of adenomas, and in healthy and tumoural tissues from CRC patients (fig. 1c-f). Besides, both healthy and tumoural specimens from CRC patients showed consistently immunoreactive germinal center cells.

CDw75 Antigen and Prognosis in Colorectal Cancer
Of 101 CRC specimens analyzed (table 1), 83 showed positive expression for CDw75 (82.2\%). Among these specimens, $27(26.7 \%)$ were found to express CDw75 weakly, whereas 42 (41.6\%) and 14 (13.9\%) showed moderate and strong expression, respectively. In healthy tissue specimens from CRC patients $(\mathrm{n}=35)$, CDw75 expression was found in 8 cases (22.9\%), with weak staining in 7 (20\%) specimens and moderate staining in $1(2.9 \%)$ specimen. Likewise, we observed CDw75 antigen expression in 19 adenomas of a total of 73 analyzed (26.0\%), the expression being weak in 16 (21.9\%) and moderate in 3 (4.1\%) (table 1).

The statistical analysis revealed significant differences between CDw75 expression in tumoural and healthy tis- 
Table 1. Immunoreactivity of CDw75 antigen in the colorectal specimens analyzed

\begin{tabular}{lllll}
\hline & \multicolumn{2}{l}{ CDw75 staining score } & & \\
\cline { 2 - 5 } & $\begin{array}{l}\text { no } \\
\text { expression }\end{array}$ & $\begin{array}{l}\text { weak } \\
\text { expression }\end{array}$ & $\begin{array}{l}\text { moderate } \\
\text { expression }\end{array}$ & $\begin{array}{l}\text { strong } \\
\text { expression }\end{array}$ \\
\hline Healthy disease-free mucosa $(\mathrm{n}=34)$ & $34(100 \%)$ & 0 & 0 & 0 \\
Inflammatory mucosa $(\mathrm{n}=19)$ & $19(100 \%)$ & 0 & 0 & 0 \\
Adenomas (n=73) & $54(74 \%)$ & $16(21.9 \%)$ & $3(4.1 \%)$ & 0 \\
Healthy tissue CRC $(\mathrm{n}=35)$ & $27(77.1 \%)$ & $7(20.0 \%)$ & $1(2.9 \%)$ & 0 \\
Tumoural tissue CRC $(\mathrm{n}=101)$ & $18(17.8 \%)$ & $27(26.7 \%)$ & $42(41.6 \%)$ & $14(13.9 \%)$ \\
\hline
\end{tabular}

Table 2. CDw75 antigen expression in colorectal specimens

\begin{tabular}{lrlllcr}
\hline Colorectal specimen & $\mathrm{n}$ & $\begin{array}{l}\text { Score } \\
\text { range }\end{array}$ & $\begin{array}{l}\text { Score } \\
\text { mean } \pm \mathrm{SD}\end{array}$ & T vs. DFM & T vs. I & T vs. A \\
\hline Disease-free mucosa & 34 & 0 & 0 & $\mathrm{p}<0.001^{\mathrm{a}}$ & $\mathrm{p}<0.001^{\mathrm{a}}$ & $\mathrm{p}<0.001^{\mathrm{a}}$ \\
Inflammatory mucosa & 19 & 0 & 0 & & $\mathrm{p}<0.001^{\mathrm{b}}$ \\
Adenomas & 73 & $0-1$ & $0.26 \pm 0.442$ & & \\
Healthy tissue (CRC) & 35 & $0-2$ & $0.26 \pm 0.505$ & & \\
Tumoural tissue (CRC) & 101 & $0-3$ & $1.51 \pm 0.945$ & & \\
\hline
\end{tabular}

The score is the intensity of CDw75 expression evaluated according to the following gradation: $0=$ without staining, $1=$ weak staining intensity, 2 = moderate staining intensity and $3=$ strong staining intensity. The intensity of the expression is indicated as the mean $\pm \mathrm{SD} .{ }^{\mathrm{a}} \mathrm{p}<0.001$ based on the Mann-Whitney U test. ${ }^{\mathrm{b}} \mathrm{p}<0.001$ based on the Wilcoxon test. $\mathrm{SD}=$ Standard deviation; $\mathrm{DFM}=$ healthy disease-free mucosa; $\mathrm{I}=$ inflammatory mucosa; $\mathrm{A}=$ adenomas; $\mathrm{H}=$ healthy tissue from $\mathrm{CRC}$; $\mathrm{T}=$ tumoural tissue from $\mathrm{CRC}$.

sues from CRC patients $(\mathrm{p}<0.001$, according to Wilcoxon's test), as well as between tumoural tissue and colorectal adenomas, inflammatory and healthy disease-free mucosa $(\mathrm{p}<0.001$, according to the Mann-Whitney $\mathrm{U}$ test) (table 2).

\section{Relationship between CDw75 Expression in CRC and Clinicopathological Features}

In order to elucidate whether CDw75 expression in CRC tumoural tissue was correlated to clinicopathological features, a correlation analysis was carried out. The $\chi^{2}$ test did not show any correlation with patient's age or sex, tumour location, size, tumour differentiation, depth of invasion and lymph node metastasis. However, statistically significant correlations were found between CDw75 expression and growth pattern $(\mathrm{p}=0.044)$, Dukes stage $(\mathrm{p}=0.002)$, TNM stage $(\mathrm{p}=0.020)$, and distant metastasis $(\mathrm{p}=0.005)$ (table 3).

Further analyses were carried out (1) comparing the cases with negative expression (score 0 ) with those that showed positive expression (scores 1-3) and (2) compar- ing the cases with low expression (score 0 or 1 ) with those with high expression (score 2 or 3). In both analyses, no significant correlations were found between CDw75 staining groups and clinicopathological features (data not shown).

A correlation analysis of CDw75 expression in colorectal adenomas with clinicopathological features was also performed, but no associations were found (data not shown).

\section{Relationship between CDw75 Expression and Tumour Recurrence}

To study the influence of CDw75 expression on the prognosis of CRC patients, a 5-year survival analysis was carried out. The analysis was performed on 78 of the 101 patients initially included in the study. During the postsurgery follow-up, recurrences were detected in 22 of the 78 patients (21.8\%): local recurrences in 6 cases and distant metachronous metastases in 16 cases.

The results obtained according to the Kaplan-Meier method and the log-rank test indicated no difference in 
Table 3. Relationship between patients' clinicopathological features and CDw75 antigen expression in colorectal tumour specimens

\begin{tabular}{|c|c|c|c|c|c|}
\hline \multirow{2}{*}{$\begin{array}{l}\text { Clinicopathological } \\
\text { features }\end{array}$} & \multicolumn{4}{|c|}{ CDw75 expression ${ }^{1}$} & \multirow[t]{2}{*}{$\mathrm{p}$ value } \\
\hline & 0 & 1 & 2 & 3 & \\
\hline \multicolumn{6}{|l|}{ Sex } \\
\hline Female & $6(15.0)$ & $12(30.0)$ & $17(42.5)$ & $5(12.5)$ & \multirow[t]{2}{*}{0.882} \\
\hline Male & $12(19.7)$ & $15(24.5)$ & $25(41.0)$ & $9(14.8)$ & \\
\hline \multicolumn{6}{|l|}{ Age } \\
\hline$<70$ years & $6(17.6)$ & $10(29.4)$ & $12(35.4)$ & $6(17.6)$ & \multirow[t]{3}{*}{0.932} \\
\hline $70-76$ years & $7(20.0)$ & $8(22.8)$ & $15(42.9)$ & $5(14.3)$ & \\
\hline$>76$ years & $5(15.6)$ & $9(28.1)$ & $15(46.9)$ & $3(9.4)$ & \\
\hline \multicolumn{6}{|l|}{ Tumour location } \\
\hline Colon, proximal & $5(25.0)$ & $2(10.0)$ & $10(50.0)$ & $3(15.0)$ & \multirow[t]{3}{*}{0.410} \\
\hline Colon, distal & $5(18.5)$ & $8(29.6)$ & $9(33.4)$ & $5(18.5)$ & \\
\hline Rectum & $8(16.0)$ & $17(34.0)$ & $21(42.0)$ & $4(8.0)$ & \\
\hline \multicolumn{6}{|l|}{ Tumour size } \\
\hline$<4.1 \mathrm{~cm}$ & $11(23.9)$ & $14(30.4)$ & $16(34.8)$ & $5(10.9)$ & \multirow{3}{*}{0.639} \\
\hline $4.1-5.5 \mathrm{~cm}$ & $2(8.7)$ & $7(30.4)$ & $10(43.5)$ & $4(17.4)$ & \\
\hline$>5.5 \mathrm{~cm}$ & $4(14.3)$ & $6(21.4)$ & $13(46.4)$ & $5(17.9)$ & \\
\hline \multicolumn{6}{|l|}{ Growth pattern } \\
\hline Polypoid & $10(23.8)$ & $13(31.0)$ & $17(40.5)$ & $2(4.7)$ & \multirow[t]{2}{*}{$0.044^{\mathrm{a}}$} \\
\hline Non-polypoid & $6(10.9)$ & $12(21.8)$ & $25(45.5)$ & $12(21.8)$ & \\
\hline \multicolumn{6}{|l|}{ Tumour differentiation } \\
\hline Well differentiated & $0(0)$ & $1(25.0)$ & $2(50.0)$ & $1(25.0)$ & \multirow[t]{3}{*}{0.070} \\
\hline Moderately differentiated & $9(11.7)$ & $24(31.2)$ & $34(44.1)$ & $10(13.0)$ & \\
\hline Poorly differentiated & $0(0)$ & $0(0)$ & $1(25.0)$ & $3(75.0)$ & \\
\hline \multicolumn{6}{|l|}{ Dukes stage } \\
\hline A & $4(30.8)$ & $5(38.5)$ & $3(23.1)$ & $1(7.6)$ & \multirow[t]{4}{*}{$0.002^{\mathrm{b}}$} \\
\hline $\mathrm{B}$ & $9(23.1)$ & $8(20.5)$ & $14(35.9)$ & $8(20.5)$ & \\
\hline $\mathrm{C}$ & $5(12.8)$ & $12(30.8)$ & $22(56.4)$ & $0(0)$ & \\
\hline $\mathrm{D}$ & $0(0)$ & $2(20.0)$ & $3(30.0)$ & $5(50.0)$ & \\
\hline \multicolumn{6}{|l|}{ pTNM classification } \\
\hline \multicolumn{6}{|l|}{ pT (primary tumour extent) } \\
\hline pT1 & $1(50.0)$ & $0(0)$ & $1(50.0)$ & $0(0)$ & \multirow[t]{4}{*}{0.376} \\
\hline pT2 & $4(28.6)$ & $6(42.9)$ & $3(21.4)$ & $1(7.1)$ & \\
\hline pT3 & $11(15.5)$ & $19(26.8)$ & $32(45.1)$ & $9(12.6)$ & \\
\hline pT4 & $2(14.3)$ & $2(14.3)$ & $6(42.8)$ & $4(28.6)$ & \\
\hline \multicolumn{6}{|l|}{ pN (lymph node metastasis) } \\
\hline pNo & $13(23.2)$ & $13(23.2)$ & $19(33.9)$ & $11(19.7)$ & \multirow[t]{2}{*}{0.059} \\
\hline $\mathrm{pN} 1 / \mathrm{N} 2$ & $5(11.1)$ & $14(31.1)$ & $23(51.1)$ & $3(6.7)$ & \\
\hline pM (distant metastasis) & & & & & \\
\hline pM0 & $18(19.8)$ & $25(27.5)$ & $39(42.9)$ & $9(9.8)$ & $0.005^{\mathrm{a}}$ \\
\hline pM1 & $0(0)$ & $2(20.0)$ & $3(30.0)$ & $5(50.0)$ & \\
\hline TNM stage & & & & & \\
\hline I & $4(30.8)$ & $5(38.5)$ & $3(23.1)$ & $1(7.6)$ & $0.020^{\mathrm{b}}$ \\
\hline IIa & $9(25.0)$ & $8(22.2)$ & $12(33.4)$ & $7(19.4)$ & \\
\hline IIb & $0(0)$ & $0(0)$ & $2(66.7)$ & $1(33.3)$ & \\
\hline IIIa & $1(50.0)$ & $1(50.0)$ & $0(0)$ & $0(0)$ & \\
\hline IIIb & $2(9.5)$ & $6(28.6)$ & $13(61.9)$ & $0(0)$ & \\
\hline IIIC & $2(12.5)$ & $5(31.3)$ & $9(56.2)$ & $0(0)$ & \\
\hline IV & $0(0)$ & $2(20.0)$ & $3(30.0)$ & $5(50.0)$ & \\
\hline
\end{tabular}

Figures in parentheses are percentages. ${ }^{\mathrm{a}} \mathrm{p}<0.05$, based on Fisher's exact probability test or ${ }^{\mathrm{b}}$ on the $\chi^{2}$ test. ${ }^{1}$ According to the staining results scored from no expression (0) to weak (1), moderate (2) or strong (3) expression. 
Table 4. Univariate analysis of factors affecting disease-free survival

\begin{tabular}{|c|c|c|c|}
\hline Clinicopathological features & $\mathrm{n}$ & $\begin{array}{l}\text { Survival } \\
\text { rate, } \%\end{array}$ & $\mathrm{p}$ value \\
\hline \multicolumn{4}{|l|}{ Sex } \\
\hline Female & 34 & 75.5 & \multirow[t]{2}{*}{0.364} \\
\hline Male & 44 & 66.0 & \\
\hline \multicolumn{4}{|l|}{ Age } \\
\hline$<70$ years & 24 & 70.1 & \multirow[t]{3}{*}{0.888} \\
\hline $70-76$ years & 31 & 72.6 & \\
\hline$>76$ years & 23 & 66.1 & \\
\hline \multicolumn{4}{|l|}{ Tumour location } \\
\hline Colon, proximal & 17 & 70.6 & \multirow[t]{3}{*}{0.731} \\
\hline Colon, distal & 17 & 63.1 & \\
\hline Rectum & 42 & 75.3 & \\
\hline \multicolumn{4}{|l|}{ Tumour size } \\
\hline$<4.1 \mathrm{~cm}$ & 38 & 72.6 & \multirow[t]{3}{*}{0.959} \\
\hline $4.1-5.5 \mathrm{~cm}$ & 15 & 73.3 & \\
\hline$>5.5 \mathrm{~cm}$ & 22 & 69.9 & \\
\hline \multicolumn{4}{|l|}{ Growth pattern } \\
\hline Polypoid & 34 & 72.1 & \multirow[t]{2}{*}{0.878} \\
\hline Non-polypoid & 42 & 67.6 & \\
\hline \multicolumn{4}{|l|}{ Dukes stage } \\
\hline A & 12 & 83.3 & \multirow[t]{3}{*}{0.077} \\
\hline $\mathrm{B}$ & 34 & 80.3 & \\
\hline $\mathrm{C}$ & 32 & 56.1 & \\
\hline \multicolumn{4}{|l|}{ pTNM classification } \\
\hline \multicolumn{4}{|c|}{$\mathrm{pT}$ (primary tumour extent) } \\
\hline $\mathrm{pT} 1$ & 2 & 100 & \multirow[t]{4}{*}{0.209} \\
\hline pT2 & 13 & 84.6 & \\
\hline pT3 & 54 & 70.0 & \\
\hline pT4 & 9 & 44.4 & \\
\hline \multicolumn{4}{|c|}{ pN (lymph node metastasis) } \\
\hline pNo & 46 & 81.0 & \multirow[t]{2}{*}{$0.024^{\mathrm{a}}$} \\
\hline $\mathrm{pN} 1 / \mathrm{N} 2$ & 32 & 56.1 & \\
\hline \multicolumn{4}{|l|}{ TNM stage } \\
\hline I & 12 & 83.3 & \multirow[t]{6}{*}{0.177} \\
\hline IIa & 32 & 83.0 & \\
\hline IIb & 2 & 50.0 & \\
\hline IIIa & 2 & 100 & \\
\hline IIIb & 17 & 52.3 & \\
\hline IIIc & 13 & 53.8 & \\
\hline \multicolumn{4}{|l|}{ CDw75 expression } \\
\hline Negative (0) & 15 & 65.5 & \multirow[t]{4}{*}{0.398} \\
\hline Weak (1) & 23 & 68.3 & \\
\hline Moderate (2) & 32 & 67.6 & \\
\hline Strong (3) & 8 & 100 & \\
\hline Negative $(0)$ & 15 & 65.5 & \multirow[t]{2}{*}{0.424} \\
\hline Positive $(1,2,3)$ & 63 & 71.4 & \\
\hline Low $(0,1)$ & 38 & 66.9 & 0.381 \\
\hline $\operatorname{High}(2,3)$ & 40 & 73.2 & \\
\hline
\end{tabular}

${ }^{\mathrm{a}} \mathrm{p}<0.05$ based on the log-rank test. disease-free survival rate between the groups of patients established according to the degree of CDw75 staining (table 4; fig. 2a-c). However, univariate analysis revealed that patient prognosis was influenced by lymph node metastasis $(\mathrm{p}=0.024)$ (table 4$)$. Finally, multivariate Cox regression analysis showed that lymph node metastasis was the only variable with independent prognostic value for predicting disease-free survival of CRC patients ( $\mathrm{p}=$ 0.018 , table 5).

\section{Discussion}

CDw75 epitope is an $\alpha(2,6)$-sialylated antigen synthesized by the ST6Gal I enzyme. This antigen has been little studied in solid organ tumours. Nevertheless, several studies have revealed an increase in ST6Gal I activity in colorectal carcinomas, and an association between high enzyme levels and CRC progression [7-11].

In a previous study, we reported enhanced CDw75 expression in CRC specimens compared with healthy colorectal specimens [22]. The main objective of this work was to study the influence of CDw75 expression in tumour recurrences in patients with CRC. In addition, we analyzed CDw75 expression in a wide collection of colorectal adenomas, and in healthy and tumoural tissue specimens from CRC patients with the purpose to elucidate their implication in the development and progression of CRC. To obtain a complete picture of the malignant transformation process of colorectal tissue, we also included specimens from both disease-free individuals and from patients with inflammatory bowel disease.

Immunohistochemical analysis showed no expression of CDw75 antigen in healthy disease-free and inflammatory colorectal mucosa. However, we observed positive CDw75 staining in $22.9 \%$ of healthy tissue specimens from CRC patients. The expression detected in this tissue could be related to the tumour process since we have not observed expression of CDw75 in colorectal mucosa from disease-free patients. Concerning the colorectal adenomas, we detected expression of CDw75 antigen in $26 \%$ of the specimens, similar to our previous observations [22] in a study in which a smaller number of adenomas were analyzed. The majority of the adenomas showed weak CDw75 expression and the correlation analysis between the expression and the clinicopathological features did not reveal any association. These results suggest that the antigen is not implicated in the early stages of CRC development through the classical adenoma-carcinoma pathway. 

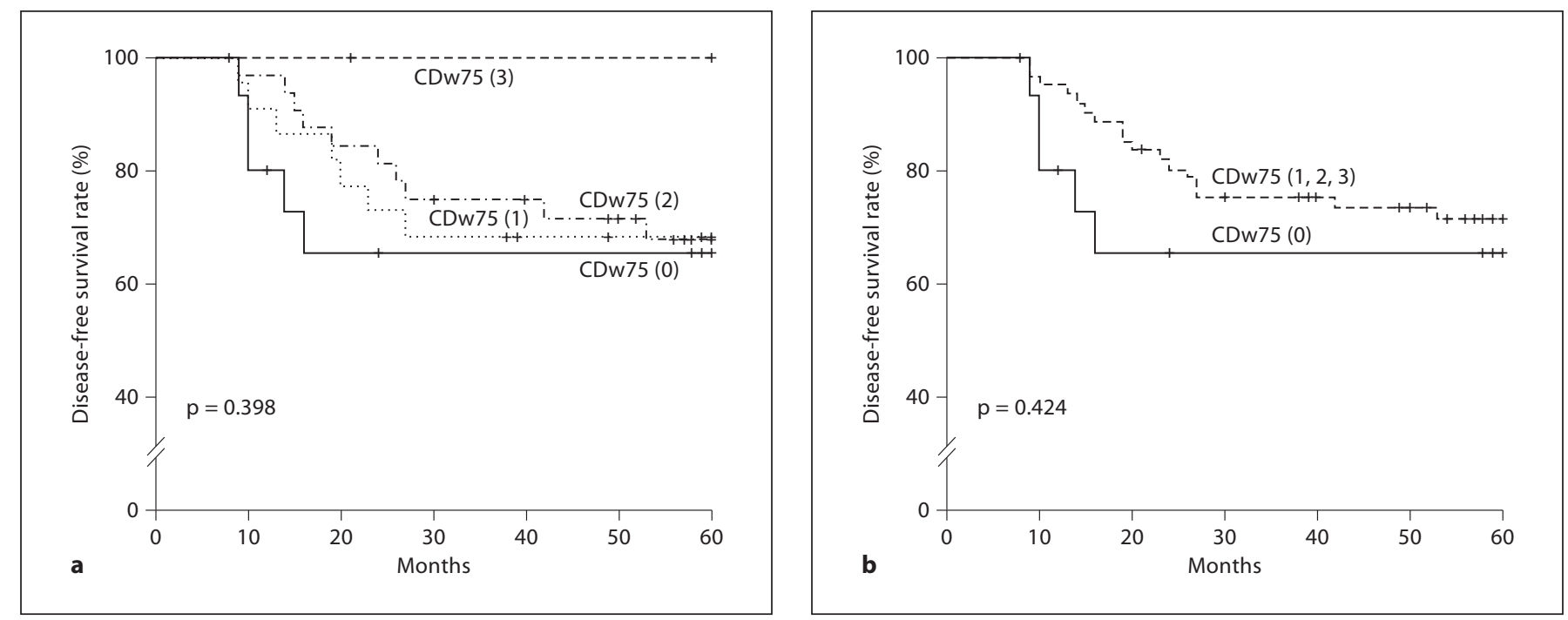

Fig. 2. Disease-free survival of CRC patients in relation to immunohistochemical CDw75 antigen expression. The staining results were scored as no expression (0), weak (1), moderate (2) or strong (3) expression (a), no expression (0) and positive expression (1, 2 or 3 ) (b) or low expression (0 or 1) and high expression (2 or 3) (c).

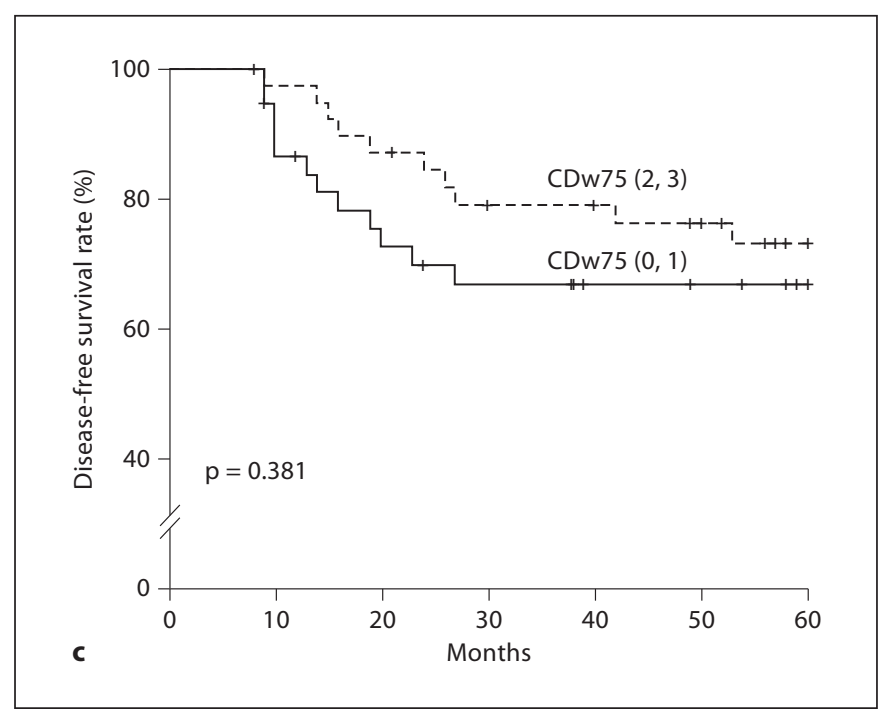

Although CDw75 expression in colorectal adenomas has not been analyzed previously, different studies have reported the expression of $\alpha(2,6)$-sialylated oligosaccharides in colorectal adenomas using SNA lectin [27, 28]. Nevertheless, the specificity of the SNA lectin differs from that of the anti-CDw75 monoclonal antibody. This lectin recognizes oligosaccharide chains bearing a galactose residue sialylated in the $\alpha(2,6)$-position (sequence present in the CDw75 antigen) as well as in the $\alpha(2,6)$ sialylated GalNac residue. This last structure, known as the sialyl-Tn antigen, is mainly expressed in tumours in Table 5. Multivariate analysis of predictive factors for diseasefree survival

\begin{tabular}{|c|c|c|c|}
\hline Clinicopathological features & $\begin{array}{l}\text { Relative } \\
\text { risk }\end{array}$ & $95 \%$ CI & $\mathrm{p}$ value \\
\hline \multicolumn{4}{|l|}{$\begin{array}{l}\text { pN (lymph node metastasis) } \\
\text { pN0 (absent) vs. } \\
\text { pN1/N2 (present) }\end{array}$} \\
\hline $\begin{array}{l}\mathrm{CI}=\text { Confidence interval } \\
{ }^{\mathrm{a}} \mathrm{p}<0.05 \text { based on Cox } \mathrm{r}\end{array}$ & ssion a & ysis. & \\
\hline
\end{tabular}
various organs although it has also been detected in healthy colorectal tissue $[29,30]$. 
Regarding the tumoural specimens analyzed, $82.2 \%$ of the cases expressed CDw75 antigen, in accordance with our previous results [22]. However, Elpek et al. [20] detected the antigen in $51 \%$ of CRC specimens studied. The overexpression of CDw75 antigen in tumoural tissue compared with healthy tissue from CRC patients and in colorectal adenomas was corroborated statistically. Moreover, the absence of CDw75 expression in specimens of inflammatory bowel disease indicates that the enhanced antigen expression is specific of the tumour stage rather than being a consequence of the tumour-associated inflammation.

The correlation analysis carried out to study the relationship between antigen expression and clinicopathological features revealed a statistically significant association between CDw75 expression and tumour aggressiveness. We observed an increase in moderate or strong CDw75 expression in advanced tumour stages according to Dukes and TNM classifications, in non-polypoid tumours (tumours that expand progressively infiltrating the intestinal wall) as well as in cases with distant metastasis. Similar results have been reported regarding a statistically significant association between the expression of CDw75 in CRC and different characteristics of tumour aggressivenes, such as the degree of tumour infiltration into the intestinal wall, tumour stage, lymph node infiltration and distant metastasis [20]. Taking into account these results, we hypothesize that $\mathrm{CDw} 75$ antigen could be implicated in local tumour progression through the intestinal wall. In relation to this, it has been found that the increased cell surface $\alpha(2,6)$-sialylation affects the adhesion of breast carcinoma cells, reducing their homotypic aggregation [31]. Similarly, recent studies have revealed the enhancement of $\beta 1$-integrin $\alpha(2,6)$-sialylation associated with progression of colorectal and mammary tumours [32, 33].

As far as we know, the relationship between CDw75 expression in CRC and patient survival has not been reported previously since the only report focusing on the expression of CDw75 in CRC did not analyze its prognostic value [20]. However, it has been reported that the strong SNA lectin reactivity in CRC is an independent prognostic factor that predicts overall survival [34], but as previously discussed, SNA lectin recognizes both CDw75 and sialyl-Tn antigens. In this work, the correlation analysis showed an association between high CDw75 expression and distant metastasis. This finding could indicate a positive correlation between CDw75 expression and tumour recurrence. However, the survival analysis did not reveal an association between antigen expression and disease-free survival. The fact that CDw75 antigen was expressed in the majority of the carcinomas analyzed, limits its usefulness as a prognostic marker. Previous studies reporting an association between CDw75 expression and overall survival have demonstrated that CDw75 antigen expression in gastric cancer is associated with a poor prognosis $[19,21]$. Nevertheless, we consider that disease-free survival is the parameter that better represents the patient's post-surgical evolution, since many aged CRC patients die of non-cancerous processes. Thus, an association between CDw75 expression in gastric or colorectal adenocarcinoma and tumour recurrence has not been reported to date.

In conclusion, we have demonstrated that CDw75 expression in CRC is not a prognostic factor for predicting disease-free survival. However, we observed an increase in CDw75 expression paralleling the progressive malignant transformation of healthy disease-free colorectal mucosa to adenocarcinomatous mucosa. Furthermore, the high expression levels of CDw75 antigen were associated with advanced tumour stages and distant metastasis. Therefore, our results suggest that the high CDw75 expression may be a marker of progression and of the malignant potential of CRC. Nevertheless, further studies are needed to elucidate the mechanisms leading to CDw75 antigen overexpression in CRC and the role of the antigen in tumour progression.

\section{Acknowledgments}

This research would not have been possible without the collaboration of the Pathology Service of the University Hospital Complex (Ourense, Spain). We also would like to thank Profs. Jacobo de Uña and Carlos Villaverde (University of Vigo, Spain) for their advice on statistics, and Prof. Miguel Angel Pombal's research group for technical assistance (University of Vigo, Spain). This work was supported by a grant from Xunta de Galicia (XUGA PGIDIT02BTF30101PR). S.V.-P. and L.M.-R. were supported by predoctoral fellowships from Xunta de Galicia.

References

1 Hakomori S: Aberrant glycosylation in tumors and tumor-associated carbohydrate antigens. Adv Cancer Res 1989;52:257-331.

2 Dennis JW, Laferte S: Tumor cell surface carbohydrate and the metastatic phenotype. Cancer Metastasis Rev 1987;5:185-204.

3 Dall'Olio F, Chiricolo M: Sialyltransferases in cancer. Glycoconj J 2001;18:841-850.

4 Dall'Olio F: The sialyl- $\alpha 2,6$-lactosaminyl structure: biosynthesis and functional role. Glycoconj J 2000;17:669-676. 
5 Takashima S, Tsuji S, Tsujimoto M: Characterization of the second type of human $\beta$-galactoside $\alpha 2,6$-sialyltransferase (ST6Gal II), which sialylates Gal $\beta 1,4 \mathrm{GlcNAc}$ structures on oligosaccharides preferentially. Genomic analysis of human sialyltransferase genes. J Biol Chem 2002;277:45719-45728.

6 Krzewinski-Recchi MA, Julien S, Juliant S, Teintenier-Lelièvre M, Samyn-Petit B, Montiel MD, Mir AM, Cerutti M, Harduin-Lepers A, Delannoy P: Identification and functional expression of a second human $\beta$-galactoside $\alpha 2,6$-sialyltransferase, ST6Gal II. Eur J Biochem 2003;270:950-961.

7 Dall'Olio F, Malagolini N, di Stefano G, Minni F, Marrano D, Serafini-Cessi F: Increased CMP-NeuAc:Gal $\beta 1,4$ GlcNAc-R $\alpha 2,6$ sialyltransferase activity in human colorectal cancer tissues. Int J Cancer 1989; 44:434-439.

$\checkmark 8$ Gessner P, Riedl S, Quentmaier A, Kemmner W: Enhanced activity of CMP-NeuAc: Gal $\beta 1-4 G l c N A c: \alpha 2,6$-sialyltransferase in metastasizing human colorectal tumor tissue and serum of tumor patients. Cancer Lett 1993;75:143-149.

>9 Kemmner W, Krück D, Schlag P: Different sialyltransferase activities in human colorectal carcinoma cells from surgical specimens detected by specific glycoprotein and glycolipid acceptors. Clin Exp Metastasis 1994;12: 245-254.

-10 Vázquez-Martín C, Gil-Martín E, Fernández-Briera A: Elevation of ST6Gal I activity in malignant and transitional tissue in human colorectal cancer. Oncology 2005;69: 436-444.

-11 Lise M, Belluco C, Perera SP, Patel R, Thomas $\mathrm{P}$, Ganguly A: Clinical correlations of $\alpha-$ 2,6-sialyltransferase expression in colorectal cancer patients. Hybridoma 2000;19:281286.

12 Ghosh S, Bandulet C, Nitschke L: Regulation of B cell development and B cell signalling by CD22 and its ligands $\alpha 2,6$-linked sialic acids. Int Immunol 2006;18:603-611.
13 Guy K, Andrew JM: Expression of the CDw75 ( $\beta$-galactoside $\alpha 2,6$-sialyltransferase) antigen on normal cells and in B-cell chronic lymphocytic leukaemia. Immunology 1991;74:206-214.

14 Schmid C, Pan L, Diss T, Isaacson PG: Expression of B-cell antigens by Hodgkin's and Reed-Sternberg cells. Am J Pathol 1991;139: 701-707.

15 Ohsawa M, Kanno H, Machii T, Aozasa K: Immunoreactivity of neoplastic and nonneoplastic monocytoid B lymphocytes for DBA.44 and other antibodies. J Clin Pathol 1994;47:928-932.

16 de Lau WB, Kuipers J, Peters PJ, Lokhorst HM, Clevers H, Bast BJ: Putative myeloma precursor cells expressing 2,6 sialic acidmodified antigens actually belong to the erythroid lineage. Leuk Res 1998;22:163-173.

17 David L, Nesland JM, Funderud S, Sobrinho-Simões M: CDw75 antigen expression in human gastric carcinoma and adjacent mucosa. Cancer 1993;72:1522-1527.

18 Reed W, Erikstein BK, Funderud S, Lilleng R, Tvedt K, Nesland JM: CDw75 antigen expression in breast lesions. Pathol Res Pract 1993;189:394-398.

19 Elpek GO, Gelen T, Karpuzoğlu G, Karpuzoğlu T, Keles N: Clinicopathologic evaluation of CDw75 antigen expression in patients with gastric carcinoma. J Pathol 2001;193: 169-74.

20 Elpek GO, Gelen T, Karpuzoğlu G, Karpuzoğlu T, Aksoy NH, Keles N: Clinicopathologic evaluation of CDw75 antigen expression in colorectal adenocarcinomas. Pathol Oncol Res 2002;8:175-182.

21 Shen L, Li HX, Luo HS, Shen ZX, Tan SY, Guo J, Sun J: CDw75 is a significant histopathological marker for gastric carcinoma. World J Gastroenterol 2004;10:1682-1685.

22 Costa-Nogueira C, Villar-Portela S, Cuevas E, Gil-Martín E, Fernández-Briera A: Synthesis and expression of CDw75 antigen in human colorectal cancer. BMC Cancer 2009; 9:431.

23 Sobin LH, Wittekind C: International Union Against Cancer (UICC) TNM Classification of Malignant Tumors, ed 6. New York, Wiley-Liss, 2002.
24 Kaplan EL, Meier P: Nonparametric estimation from incomplete observation. J Am Stat Assoc 1958;53:457-481.

25 Mantel N: Evaluation of survival data and two new rank order statistics arising in its consideration. Cancer Chemother Rep 1966; 50:163-170

26 Cox DR: Regression models and life-tables. J R Stat Soc Ser B-Stat Methodol 1972;34: 187-220.

27 Sata T, Roth J, Zuber C, Stamm B, Heitz PU: Expression of $\alpha 2,6$-linked sialic acid residues in neoplastic but not in normal human colonic mucosa. Am J Pathol 1991;139:14351448.

28 Dall'Olio F, Trerè D: Expression of $\alpha 2,6$-sialylated sugar chains in normal and neoplastic colon tissues. Detection by digoxigeninconjugated Sambucus nigra agglutinin. Eur J Histochem 1993;37:257-265.

29 Podolsky DK: Oligosaccharide structures of human colonic mucin. J Biol Chem 1985;260: 8262-8271.

-30 Vázquez-Martín C, Cuevas E, Gil-Martín E, Fernández-Briera A: Correlation analysis between tumorous associated antigen sialylTn expression and ST6GalNAc I activity in human colon adenocarcinoma. Oncology 2004;67:159-165.

31 Lin S, Kemmner W, Grigull S, Schlag PM: Cell surface $\alpha 2,6$-sialylation affects adhesion of breast carcinoma cells. Exp Cell Res 2002;276:101-110.

32 Seales EC, Jurado GA, Brunson BA, Wakefield JK, Frost AR, Bellis SL: Hypersialylation of $\beta 1$ integrins, observed in colon adenocarcinoma, may contribute to cancer progression by up-regulating cell motility. Cancer Res 2005;65:4645-4652.

33 Hedlund M, Ng E, Varki A, Varki NM: $\alpha 2-6$ Linked sialic acids on $\mathrm{N}$-glycans modulate carcinoma differentiation in vivo. Cancer Res 2008;68:388-394.

34 Vierbuchen MJ, Fruechtnicht W, Brackrock S, Krause KT, Zienkiewicz TJ: Quantitative lectinhistochemical and immunohistochemical studies on the occurrence of $\alpha(2,3)$ and $\alpha(2,6)$-linked sialic acid residues in colorectal carcinomas. Cancer 1995;76:727735 . 